\title{
Biochar effects in the growing and control of biotic and abiotic stress in Astrophytum myriostigma and Astrophytum capricorne
}

\author{
Domenico Prisa* \\ CREA Research Centre for Vegetable and Ornamental Crops, Council for Agricultural Researchand Economics, Via dei \\ Fiori 8, 51012 Pescia, PT, Italy.
}

GSC Biological and Pharmaceutical Sciences, 2021, 16(01), 186-194

Publication history: Received on 22 June 2021; revised on 26 July 2021; accepted on 28 July 2021

Article DOI: https://doi.org/10.30574/gscbps.2021.16.1.0211

\begin{abstract}
Research goal: Based on the information found in the literature on biochar, its ability to improve the quality and yield of productions and to influence soil microflora. In this work, studies were carried out at different concentrations in pots to assess whether the addition of this material to the growing medium can influence the growth and control of biotic and abiotic stresses on Astrophytum myriostigma and Astrophytum capricorne.
\end{abstract}

Materials and Methods: The experiments, started in June 2020, were conducted in the greenhouses of CREA-OF in Pescia (PT), Tuscany, Italy $\left(43^{\circ} 54^{\prime} \mathrm{N} 10^{\circ} 41^{\prime} \mathrm{E}\right)$. The experimental groups were: i) group control, irrigated with water and substrate previously fertilized; ii) group with biochar $5 \%$, irrigated with water and substrate previously fertilized; iii) group with biochar $10 \%$, irrigated with water and substrate previously fertilized; iv) group with biochar $15 \%$, irrigated with water and substrate previously fertilized; On June 30,2021, plant height and circumference, number and length of thorns, vegetative weight, root weight, number of fruits, fruit weight, number of flowers, flower life, plants dead from cold stress, plants dead from Rhizoctonia solani.

Results and Discussion: The test showed a significant increase in the agronomic parameters analyzed in biochartreated plants on Astrophytum myriostigma and Astrophytum capricorne. The test also showed an improvement in plant quality in terms of increased number of thorns, fruits, flowers and increased resistance to cold stress and the pathogen Rhizoctonia solani. The trial also showed that an increase in substrate biochar content of $10 \%-15 \%$ improved plant growth performance compared to lower $5 \%$ contents.

Conclusions: The experimentation carried out at CREA-OF in Pescia showed how the application of biochar to the cultivation substrate of Astrophytum myriostigma and Astrophytum capricorne can significantly improve the quality and the resistance to biotic and abiotic stresses of the plants. As in other experiments in the literature, the application of this soil conditioner also resulted in positive effects in the control of pathogenic fungi, particularly Rhizoctonia solani. This effect was probably mediated by the presence of microorganisms in the biochar that, in addition to having an effect on plant stimulation, may have a fundamental role in their biocontrol activity of substrate pathogens. Interesting results have also been the increase in the number of thorns, flowers and fruit duration and resistance to cold stress in plants grown with biochar.

Keywords: Cactus; Sustainable agriculture; Soil amendment; Soil fertility; Ornamental plants

\footnotetext{
${ }^{*}$ Corresponding author: Domenico Prisa

CREA Research Centre for Vegetable and Ornamental Crops, Council for Agricultural Research and Economics, Via dei Fiori 8, 51012 Pescia, PT, Italy. 


\section{Introduction}

\subsection{Astrophytum: characteristics and environment}

Astrophytums, from the Greek 'aster' (star) and 'phyton' (plant), were discovered in 1827 by Thomas Coulter who collected a plant in the Mexican state of Hidalgo that we now call $A$. ornatum, but was described in 1828 by De Condolle as Echinocactus ornatus. In 1839 Charles Lemaire gave the name A. myriostigma to a plant collected in northern Mexico. In the same year H.G. Galeotti named Cereus collicohe, which became A. myriostigma, a plant collected in San Luis Potosi. In 1845 also J.G. Zuccarini described as Echinocactus asterias a plant collected by Karwinsky two years earlier [1,2].

In 1851 Poselger found a species in Coahuila, which Dietrich described as Echinocactus capricornis, which later took the name A. capricorne. Moeller, in 1927, called Echinocactus myriostigma ssp. coahuilense a plant that in 1932 Kaiser renamed $A$. coahuilense. Various events led the Astrophytums to be classified as a subgenus of Echinocactus (Schumann), then as a tribe of Echinocactaneae (Britton \& Rose), and then as tribe VI of Notocacteae (Buxbaum). In 1922 Britton \& Rose in their important work "The Cactaceae" finally elevated Astrophytum to the rank of a genus. Subsequent and more detailed studies of the seeds with the scanning electron microscope, and DNA examinations, challenged Buxbaum's thesis without, however, definitively clarifying the systematic position of the A. that currently belong to the subfamily Cactoideae, tribe Cacteae [1,2].

Solitary plant, without sprouts, globular or columnar in shape, with a limited number of more or less prominent ribs. Green or glaucous body with the typical presence of thin white tufts (trichomes). The stem turns dark brown with age from the base. The tubercles are absent, while the spines, rigid or yielding, straight or twisted and intertwined, are only present in A. capricorne and A. ornatum. The roots are fibrous, superficial and extensive, taprooted only in $A$. asterias and $A$. caput-medusae. The flowers, funnel-shaped, diurnal, appear at the apex of the plant, they are yellow with the presence or absence of a red throat, the anthesis lasts 2-3 days. The fruit is dry, dehiscent (opens naturally), rapidly ripening, globular in shape and hairy. The dark brown seeds are shiny and smooth, 2-4 mm in size, germinate quickly and are dispersed by ants. Astrophytums are distributed from southern Texas to northern and central Mexico on calcareous, mountainous and hilly soils $[3,4,5]$.

The first known hybridiser was the French abbot Béguin who crossed $A$. myriostigma with Echinocactus ornatus towards the end of the 19th century and obtained very robust plants. In the course of the 20th century, several scholars dealt with hybridisation. In 1925 0. Sadovsky experimented with numerous crosses between different species and in $1927 \mathrm{H}$. Moller discovered that crosses do not succeed between red-throated and yellow-throated species because they evolved on different lines. From 1927 to 1971 R. Graser obtained three-ribbed specimens of $A$. myriostigma that could reproduce by inheritance. In $1944 \mathrm{M}$. Megata conducted several experiments according to scientific criteria [1, 2].

\subsection{Biochar use in agriculture}

Biochar (charcoal) is a product obtained from pyrolysis, the thermal degradation of biomass in the absence of oxygen. Pyrolysis can also produce gaseous and liquid biofuels. The half-life of biochar in soil is estimated at tens of thousands of years depending on the feedstock and pyrolysis conditions. This ensures that carbon can be stored in the soil and removed from the atmosphere. Modest additions of biochar to the soil can reduce greenhouse gas emissions from cultivated land, lowering $\mathrm{N}_{2} 0$ emissions by $80 \%$ and totally reducing methane. The effects of biochar on plant growth have a rich literature. The incorporation of biochar into the soil has led to an average increase in crop yields of $10 \%$, which vary according to the type of material. In particular, studies have reported that biochar added to soil increased soybean and pea yields [6] and birch and pine shoot and root biomass [7]. Soil application of biochar resulted in an increase in the biomass of sugi trees (Cryptomeria japonica) [8]. Furthermore, a single application of 20 tha- 1 of biochar in Colombia resulted in a 28 to $140 \%$ increase in maize yield compared to the unmodified control in the 2 nd-4th year after application [9]. The trials also reveal a $22 \%$ increase in the proportion of $\mathrm{N}$ fixed by bean (Phaseolus vulgaris) plants and an increase in biomass production and bean yield [10]. The most interesting aspect concerning biochar is certainly its ability to significantly influence soil microbiology, as found by Lehmann et al. [11]. In this review, microbial biomass increased in biochar-treated soils and led to significant changes in the composition of the microbial community and enzymatic activities in the rhizosphere. Generally, an increase in the phyla Actinobacteria and Bacteriodetes was noted. Soil amendment with biochar often results in a significant increase in symbiotic plant-mycorrhizal fungi [12]. In addition to arbuscular mycorrhizal fungi (AM) in promoting plant growth, the effects of selected strains belonging to the genera Pseudomonas, Bacillus and Trichoderma are known to enhance plant growth in many growing systems $[13,14,15]$. However, few studies have examined the proliferation of plant growth-promoting rhizobacteria/fungus (PGPR/F) in biochar-enriched soils [16], and especially little research has evaluated the use of biochar in pots for cactus cultivation. 
Based on the information found in the literature on biochar, its ability to improve the quality and yield of productions and to influence soil microflora [17]. In this work, studies were carried out at different concentrations in pots to assess whether the addition of this material to the growing medium can influence the growth and control of biotic and abiotic stresses on Astrophytum myriostigma and Astrophytum capricorne (Figure 1).

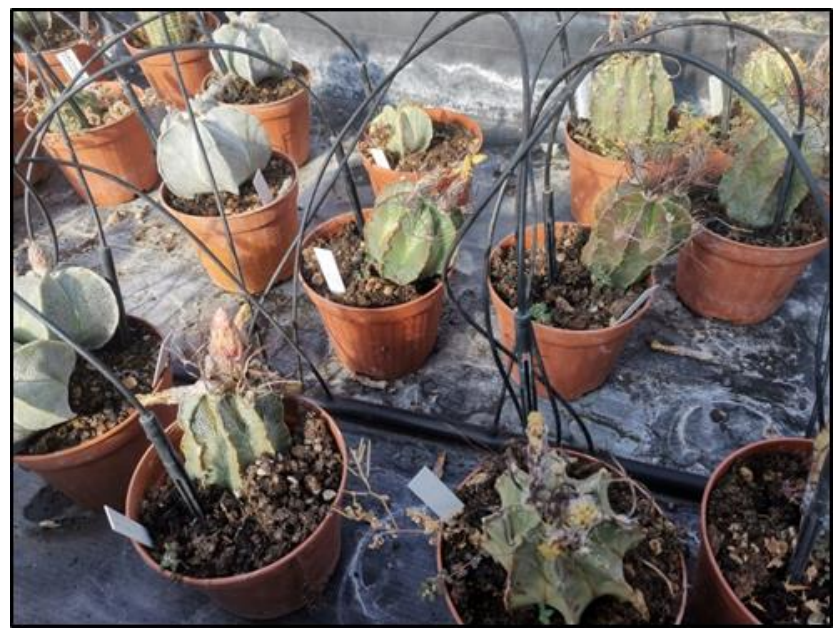

Figure 1 Detail of Astrophytum plants in pots in the greenhouses of CREA-OF in Pescia

\section{Material and methods}

\subsection{Greenhouse experiment and growing conditions}

The experiments, started in June 2020, were conducted in the greenhouses of CREA-OF in Pescia (PT), Tuscany, Italy $\left(43^{\circ} 54^{\prime} \mathrm{N} 10^{\circ} 41^{\prime} \mathrm{E}\right)$ on Astrophytum myriostigma and Astrophytum capricorne. The plants were placed in pots $\varnothing 12 \mathrm{~cm}$; 30 plants per thesis, divided into 3 replicas of 10 plants each. Plants in the control thesis, were fertilized with a controlled release fertilizer ( $3 \mathrm{~kg} \mathrm{~m}^{-3}$ Osmocote Pro®, 9-12 months with $190 \mathrm{~g} / \mathrm{kg} \mathrm{N}, 39 \mathrm{~g} / \mathrm{kg} \mathrm{P,} 83 \mathrm{~g} / \mathrm{kg} \mathrm{K}$ ) mixed with the growing medium before transplanting. The experimental groups were:

- $\quad$ group control (CTRL) (acid peat 40\% + pumice 2-4 mm 30\% + non-calcareous sand 2-4 mm 30\% ), irrigated with water and substrate previously fertilized;

- $\quad$ group with biochar 5\% (BCH5) (acid peat 35\% + biochar 5\% + pumice 2-4 mm 30\% + non-calcareous sand 2-

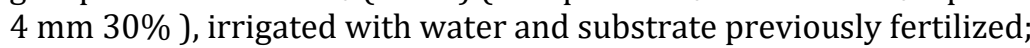

- group with biochar 10\% (BCH10) (acid peat 30\% + biochar 10\% + pumice 2-4 mm 30\% + non-calcareous sand 2-4 mm 30\% ), irrigated with water and substrate previously fertilized;

- group with biochar 15\% (BCH15) (acid peat 25\% + biochar 15\% + pumice 2-4 mm 30\% + non-calcareous sand 2-4 $\mathrm{mm} \mathrm{30 \%} \mathrm{),} \mathrm{irrigated} \mathrm{with} \mathrm{water} \mathrm{and} \mathrm{substrate} \mathrm{previously} \mathrm{fertilized;}$

The biochar of the company BioDea, presented characteristics of porosity and high structural stability, consisting of screened and selected vegetable carbon, with an organic carbon content $>60 \%$ (Table1).

The plants were watered 1 time per day, 7 days a week and grown for 12 months. The plants were irrigated with drip irrigation. The irrigation was activated by a timer whose program was adjusted weekly according to climatic conditions and the fraction of leaching. On June 30,2021, plant height and circumference, number and length of thorns, vegetative weight, root weight, number of fruits, fruit weight, number of flowers, flower life, plants dead from cold stress, plants dead from Rhizoctonia solani.

\subsection{Statistics}

The experiment was carried out in a randomized complete block design. Collected data were analysed by one-way ANOVA, using GLM univariate procedure, to assess significant $(P \leq 0.05,0.01$ and 0.001$)$ differences among treatments. Mean values were then separated by LSD multiple-range test $(P=0.05)$. Statistics and graphics were supported by the programs Costat (version 6.451) and Excel (Office 2010). 
Table 1 Characteristics of the biochar BioDea used in the test

\begin{tabular}{|l|c|}
\hline \multicolumn{1}{|c|}{ Parameter } & Value \\
\hline particle size: pass fraction $<0,5 \mathrm{~mm}$ & $12 \%$ \\
\hline$<2 \mathrm{~mm}$ & $19 \%$ \\
\hline$<5 \mathrm{~mm}$ & $43 \%$ \\
\hline total nitrogen (N) & $<0.5 \%$ \\
\hline total potassium (K) & $3020 \mathrm{mg} / \mathrm{kg}$ \\
\hline total phosphorus (P) & $0.034 \%$ \\
\hline total calcium (Ca) & $9920 \mathrm{mg} / \mathrm{kg}$ \\
\hline total magnesium (Mg) & $852 \mathrm{mg} / \mathrm{kg}$ \\
\hline total sodium (Na) & $291 \mathrm{mg} / \mathrm{kg}$ \\
\hline carbon from carbonates (C) & $<0.1 \%$ \\
\hline salinity & $110 \mathrm{mS} / \mathrm{m}$ \\
\hline pH & 9.85 \\
\hline ashes content & $5.5 \% \mathrm{s.s}$ \\
\hline
\end{tabular}

\section{Results and discussion}

The test showed a significant increase in the agronomic parameters analyzed in biochar-treated plants on Astrophytum myriostigma and Astrophytum capricorne. The test also showed an improvement in plant quality in terms of increased number of thorns, fruits, flowers and increased resistance to cold stress and the pathogen Rhizoctonia solani. The trial also showed that an increase in substrate biochar content of 10\%-15\% improved plant growth performance compared to lower $5 \%$ contents.

Specifically, in (Table 2) on Astrophytum myriostigma, it is shown that treatment (BCH15) significantly improved plant height with $15.49 \mathrm{~cm}$, compared to (BCH10) with $11.17 \mathrm{~cm}$, (BCH5) with $9.50 \mathrm{~cm}$ and (CTRL) with $9.15 \mathrm{~cm}$. The use of biochar significantly increased plant circumference, in fact the best treatment was (BCH15) with $17.29 \mathrm{~cm}$, followed by (BCH10) and (BCH5) with 16.40 and 16.01 respectively, finally the (CTRL) with $14.88 \mathrm{~cm}$. It also showed an increase in vegetative weight, 71.52 $\mathrm{g}$ (BCH15), $70.32 \mathrm{~g}$ and $69.54 \mathrm{~g}$ (BCH10) and (BCH5) respectively, finally 67.31 of the untreated control (Figure 2B). The roots weight also increased with the use of biochar, in fact a weight of $45.35 \mathrm{~g}$ is found in (BCH15), in (BCH10) $43.91 \mathrm{~g}$, in (BCH5) $42.70 \mathrm{~g}$ and in the control $41.30 \mathrm{~g}$ (Figure 3A,3B). The test also showed that the use of biochar in the substrate can positively influence the resistance to cold stress, in fact only in the control there was significant mortality with 1.60 dead plants and a significant reduction in plant mortality from Rhizoctonia solani, again only in the untreated control there was a mortality of 0.80 plants.

In (Table 3) on Astrophytum myriostigma it is shown that the use of biochar significantly increased the number of thorns in all treatments compared to (CTRL). Treatment (BCH15) was best in terms of thorns length with $5.19 \mathrm{~cm}$, followed by (BCH10) with $4.73 \mathrm{~cm},(\mathrm{BCH} 5)$ with $4.30 \mathrm{~cm}$ and the control with $3.42 \mathrm{~cm}$. There were no significant differences between treatments in number and weight of fruits and flower life, while treatment (BCH15) was the best in number of flowers with 2.41, followed by (BCH10) with 1.63, (BCH5) with 1.24 and control with 1.00 .

In (Table 4) on Astrophytum capricorne, it is shown that treatment (BCH15) significantly affected plant height with 17.49 $\mathrm{cm}$, followed by (BCH10) with $16.21 \mathrm{~cm}$, (BCH5) with $14.88 \mathrm{~cm}$ and control with $13.32 \mathrm{~cm}$. Addition of biochar to the growing medium also significantly increased plant circumference, the best treatment was (BCH15) with $22.33 \mathrm{~cm}$, followed by (BCH10) and (BCH5) with 20.93 and 20.84 respectively, finally the (CTRL) with $19.74 \mathrm{~cm}$. There was also an increase in vegetative weight, $95.26 \mathrm{~g}$ (BCH15), $93.40 \mathrm{~g}$ (BCH10), $92.06 \mathrm{~g}$ (BCH5) and finally the control with 89.69 $\mathrm{g}$ (Figure 2A). Roots weight also increased with the use of biochar, in fact a weight of $70.56 \mathrm{~g}$ was found in (BCH15), in (BCH10) $67.95 \mathrm{~g}$, in (BCH5) $65.96 \mathrm{~g}$ and in the control $62.90 \mathrm{~g}$ (Figure 3C). Even on Astrophytum capricorne, it is found that the use of biochar affects the resistance to cold stress (Figure 5), only in the control there was a mortality of 1.21 
plants and towards Rhizoctonia solani, in (BCH5) and in (CTRL) respectively there was a mortality of 0.82 and 1.63 plants died due to the pathogen.

In (Table 5) on Astrophytum capricorne showed an increase in the number of thorns per plant, 19.41 (BCH15), 16.83 (BCH10), 14.28 (BCH5) and at last 10.22 of the control. Treatment (BCH15) showed an increase in thorns length with $5.30 \mathrm{~cm}$, succeeded by (BCH10) with $4.23 \mathrm{~cm}$, (BCH5) with $4.08 \mathrm{~cm}$ and (CTRL) with $3.47 \mathrm{~cm}$ (Figure 4A). On Astrophytum capricorne, the addition of biochar to the substrate showed an increase in the number of fruits per plant in theses (BCH15) and (BCH10) with 3.81 and 3.23, respectively, followed by (BCH5) with 2.20 and (CTRL) with 0.42 (Figure 4B). In terms of fruit weight, the (BCH15) treatment was also the best with $6.74 \mathrm{~g}$, succeeded by (BCH10) with 6.05, (BCH5) with $5.76 \mathrm{~g}$ and (CTRL) with $5.38 \mathrm{~g}$. There was also a significant increase in the number and flowers life in all these added with biochar, (BCH15) was the best thesis for both parameters with 2.41 and 2.46 days.

Biochar is obtained through the process of thermal degradation of biomass and organic waste of various origins. Biochar can be compared to charcoal even though their intended use is different.

The production process, type of feedstock, processing temperatures and pyrolysis time are the factors that influence the properties of biochar, in particular $\mathrm{pH}$, porosity and cation exchange capacity, volatile matter content, presence of organic matter, ash and carbon [18]. Biochar can be made from woody biomass (pruning waste, trees) and non-woody biomass (agricultural residues, animal waste, municipal and industrial solid waste). The usefulness of biochar is mainly due to its ability to improve and restore degraded soils, thus considered as a soil condition improvement product. In fact, the addition of biochar to soil can improve water retention capacity, $\mathrm{pH}$ increases and crop productivity [19]. As demonstrated in this experiment, in fact, the use of $10 \%-15 \%$ of biochar in the cultivation substrate of Astrophytum myriostigma and Astrophytum capricorne has determined a significant improvement in growth, root development and flower and fruit production of the plants. Several experiments have shown how biochar can affect soil microbial communities. The effect found on the reduction of cold and Rhizoctonia solani stresses on Astrophytum, can be surely related to an increase of microbial colonies in the growing medium, which can influence plant resistance and vigor and act as a biocontrol against bacterial and fungal pathogens. In addition to the aspects listed above, biochar has all the characteristics to improve soil quality and mitigate climate change, mainly by decreasing methane and nitrogen emissions from agricultural soils.

The use of biochar can affect microbial communities by altering organic matter content, water holding capacity, soil acidity, bioavailability of nutrients, and potentially toxic substances. Modifying these factors can result in an increase in soil microbial abundance and change the microbiome. All of these aspects are reflected in the activity of microorganisms, which in turn affect soil nutrient cycling, crop productivity, and resistance to biotic and abiotic stresses [20].

Table 2 Evaluation of Biochar on agronomic characters of Astrophytum myriostigma

\begin{tabular}{|c|c|c|c|c|c|c|}
\hline Groups & $\begin{array}{c}\text { PH } \\
\text { (cm) }\end{array}$ & $\begin{array}{c}\text { PC } \\
\mathbf{( c m )}\end{array}$ & $\begin{array}{c}\text { VW } \\
\mathbf{( g )}\end{array}$ & $\begin{array}{c}\text { RW } \\
\mathbf{( g )}\end{array}$ & $\begin{array}{c}\text { PCS } \\
\left(\mathbf{n}^{\circ} \mathbf{)}\right.\end{array}$ & $\begin{array}{c}\text { PRS } \\
\left(\mathbf{n}^{\circ} \mathbf{)}\right.\end{array}$ \\
\hline CTRL & $9,15 \mathrm{c}$ & $14,88 \mathrm{c}$ & $67,31 \mathrm{c}$ & $41,30 \mathrm{~d}$ & $1,60 \mathrm{a}$ & $0,80 \mathrm{a}$ \\
\hline BCH5 & $9,50 \mathrm{c}$ & $16,01 \mathrm{~b}$ & $69,54 \mathrm{~b}$ & $42,70 \mathrm{c}$ & $0,20 \mathrm{~b}$ & $0,00 \mathrm{~b}$ \\
\hline BCH10 & $11,17 \mathrm{~b}$ & $16,40 \mathrm{~b}$ & $70,32 \mathrm{~b}$ & $43,91 \mathrm{~b}$ & $0,00 \mathrm{~b}$ & $0,00 \mathrm{~b}$ \\
\hline BCH15 & $15,49 \mathrm{a}$ & $17,29 \mathrm{a}$ & $71,52 \mathrm{a}$ & $45,35 \mathrm{a}$ & $0,00 \mathrm{~b}$ & $0,00 \mathrm{~b}$ \\
\hline ANOVA & $* * *$ & $* * *$ & $* * *$ & $* * *$ & $* * *$ & $*$ \\
\hline
\end{tabular}

One-way ANOVA; n.s. - non significant; ${ }^{*},{ }^{* *},{ }^{* * *}$ - significant at $\mathrm{P} \leq 0.05,0.01$ and 0.001 , respectively; different letters for the same element indicate significant differences according to Tukey's (HSD) multiple-range test (P = 0.05). Legend: (CTRL): control; (BCH5): biochar 5 \%; $(\mathrm{BCH} 10)$ : biochar 10\%; (BCH15): biochar 15\%; PH: plant height; PC: plant circumference; VW: vegetative weight; RW: roots weight; PCS: cold stress plants dead; PRS: Rhizoctonia solani plants dead.

Long-term use of biochar positively influences the diversity and complexity of the microbial community with significant reflections in plant breeding. Particularly on ornamentally important Astrophytum cacti it can significantly improve flower number and duration. Interesting aspect also with regard to pollinating insects that in this way have more time to pollinate flowers and more availability of nutrients to get through difficult times [21]. Further experimentation will be conducted to evaluate whether biochar in addition to resulting in improved plant quality can affect flower fragrance and airborne volatile production. Very important aspects especially to evaluate if the microbial colonies present in this 
material that interact with the roots of plants can be somehow responsible for the communication that takes place in the air between different plant species.

Table 3 Evaluation of Biochar on quality characters and production of Astrophytum myriostigma

\begin{tabular}{|c|c|c|c|c|c|c|}
\hline Groups & $\begin{array}{c}\text { NT } \\
\left(\mathbf{n}^{\circ} \mathbf{)}\right.\end{array}$ & $\begin{array}{c}\text { LT } \\
\mathbf{( c m )}\end{array}$ & $\begin{array}{c}\text { FN } \\
\left(\mathbf{n}^{\circ} \mathbf{)}\right.\end{array}$ & $\begin{array}{c}\text { FW } \\
\mathbf{( g )}\end{array}$ & $\begin{array}{c}\text { FLN } \\
\mathbf{( n}^{\circ} \mathbf{)}\end{array}$ & $\begin{array}{c}\text { FLF } \\
\text { (days) }\end{array}$ \\
\hline CTRL & $5,65 \mathrm{~b}$ & $3,42 \mathrm{~d}$ & $0,00 \mathrm{a}$ & $0,00 \mathrm{~b}$ & $1,00 \mathrm{c}$ & $1,83 \mathrm{~b}$ \\
\hline BCH5 & $6,84 \mathrm{a}$ & $4,30 \mathrm{c}$ & $0,00 \mathrm{a}$ & $0,00 \mathrm{~b}$ & $1,24 \mathrm{bc}$ & $2,24 \mathrm{ab}$ \\
\hline BCH10 & $7,21 \mathrm{a}$ & $4,73 \mathrm{~b}$ & $0,64 \mathrm{a}$ & $0,91 \mathrm{ab}$ & $1,63 \mathrm{~b}$ & $2,21 \mathrm{ab}$ \\
\hline BCH15 & $6,63 \mathrm{a}$ & $5,19 \mathrm{a}$ & $0,81 \mathrm{a}$ & $1,62 \mathrm{a}$ & $2,41 \mathrm{a}$ & $2,63 \mathrm{a}$ \\
\hline ANOVA & $* * *$ & $* * *$ & $\mathrm{~ns}$ & $\mathrm{~ns}$ & $* * *$ & $\mathrm{~ns}$ \\
\hline
\end{tabular}

One-way ANOVA; n.s. - non significant; *, **, *** - significant at $\mathrm{P} \leq 0.05,0.01$ and 0.001 , respectively; different letters for the same element indicate significant differences according to Tukey's (HSD) multiple-range test $(\mathrm{P}=0.05)$. Legend: (CTRL): control; (BCH5): biochar $5 \%$; $(\mathrm{BCH} 10)$ : biochar 10\%; (BCH15): biochar 15\%; PH: plant height; PC: plant circumference; VW: vegetative weight; RW: roots weight; PCS: cold stress plants dead; PRS: Rhizoctonia solani plants dead.

Table 4 Evaluation of Biochar on agronomic characters of Astrophytum capricorne

\begin{tabular}{|c|c|c|c|c|c|c|}
\hline Groups & $\begin{array}{c}\text { PH } \\
\mathbf{( c m )}\end{array}$ & $\begin{array}{c}\text { PC } \\
\mathbf{( c m )}\end{array}$ & $\begin{array}{c}\text { VW } \\
\mathbf{( g )}\end{array}$ & $\begin{array}{c}\text { RW } \\
\mathbf{( g )}\end{array}$ & $\begin{array}{c}\text { PCS } \\
\mathbf{( n}^{\circ} \mathbf{)}\end{array}$ & $\begin{array}{c}\text { PRS } \\
\left(\mathbf{n}^{\circ}\right)\end{array}$ \\
\hline CTRL & $13,32 \mathrm{~d}$ & $19,74 \mathrm{c}$ & $89,69 \mathrm{~d}$ & $62,90 \mathrm{~d}$ & $1,21 \mathrm{a}$ & $1,63 \mathrm{a}$ \\
\hline BCH5 & $14,88 \mathrm{c}$ & $20,84 \mathrm{~b}$ & $92,06 \mathrm{c}$ & $65,96 \mathrm{c}$ & $0,44 \mathrm{~b}$ & $0,82 \mathrm{~b}$ \\
\hline BCH10 & $16,21 \mathrm{~b}$ & $20,93 \mathrm{~b}$ & $93,40 \mathrm{~b}$ & $67,95 \mathrm{~b}$ & $0,00 \mathrm{~b}$ & $0,00 \mathrm{c}$ \\
\hline BCH15 & $17,49 \mathrm{a}$ & $22,33 \mathrm{a}$ & $95,26 \mathrm{a}$ & $70,56 \mathrm{a}$ & $0,00 \mathrm{~b}$ & $0,00 \mathrm{c}$ \\
\hline ANOVA & $* * *$ & $* * *$ & $* * *$ & $* * *$ & $* *$ & $* * *$ \\
\hline
\end{tabular}

One-way ANOVA; n.s. - non significant; ${ }^{*},{ }^{* *},{ }^{* * *}$ - significant at $\mathrm{P} \leq 0.05,0.01$ and 0.001 , respectively; different letters for the same element indicate significant differences according to Tukey's (HSD) multiple-range test $(\mathrm{P}=0.05)$. Legend: (CTRL): control; (BCH5): biochar $5 \%$; $(\mathrm{BCH} 10)$ : biochar 10\%; (BCH15): biochar 15\%; PH: plant height; PC: plant circumference; VW: vegetative weight; RW: roots weight; PCS: cold stress plants dead; PRS: Rhizoctonia solani plants dead.

Table 5 Evaluation of Biochar on quality characters and production of Astrophytum capricorne

\begin{tabular}{|l|l|l|l|l|l|l|}
\hline Groups & $\begin{array}{l}\text { NT } \\
\left(\mathbf{n}^{\circ} \mathbf{)}\right.\end{array}$ & $\begin{array}{l}\text { LT } \\
\mathbf{( c m )}\end{array}$ & $\begin{array}{l}\text { FN } \\
\mathbf{( n}^{\circ} \mathbf{)}\end{array}$ & $\begin{array}{l}\text { FW } \\
\mathbf{( g )}\end{array}$ & $\begin{array}{l}\text { FLN } \\
\left(\mathbf{n}^{\circ}\right)\end{array}$ & $\begin{array}{l}\text { FLF } \\
\text { (days })\end{array}$ \\
\hline CTRL & $10,22 \mathrm{~d}$ & $3,47 \mathrm{c}$ & $0,42 \mathrm{c}$ & $5,38 \mathrm{~d}$ & $1,00 \mathrm{c}$ & $1,28 \mathrm{~b}$ \\
\hline BCH5 & $14,28 \mathrm{c}$ & $4,08 \mathrm{~b}$ & $2,20 \mathrm{~b}$ & $5,76 \mathrm{c}$ & $1,41 \mathrm{bc}$ & $1,23 \mathrm{~b}$ \\
\hline BCH10 & $16,83 \mathrm{~b}$ & $4,23 \mathrm{~b}$ & $3,23 \mathrm{a}$ & $6,05 \mathrm{~b}$ & $1,83 \mathrm{~b}$ & $1,21 \mathrm{~b}$ \\
\hline BCH15 & $19,41 \mathrm{a}$ & $5,30 \mathrm{a}$ & $3,81 \mathrm{a}$ & $6,74 \mathrm{a}$ & $2,41 \mathrm{a}$ & $2,46 \mathrm{a}$ \\
\hline ANOVA & $* * *$ & $* * *$ & $* * *$ & $* * *$ & $* *$ & $* *$ \\
\hline
\end{tabular}

One-way ANOVA; n.s. - non significant; ${ }^{*}, * *, * *-$ significant at $\mathrm{P} \leq 0.05,0.01$ and 0.001 , respectively; different letters for the same element indicate significant differences according to Tukey's (HSD) multiple-range test (P = 0.05). Legend: (CTRL): control; (BCH5): biochar $5 \%$; $(\mathrm{BCH} 10)$ : biochar 10\%; (BCH15): biochar 15\%; PH: plant height; PC: plant circumference; VW: vegetative weight; RW: roots weight; PCS: cold stress plants dead; PRS: Rhizoctonia solani plants dead. 


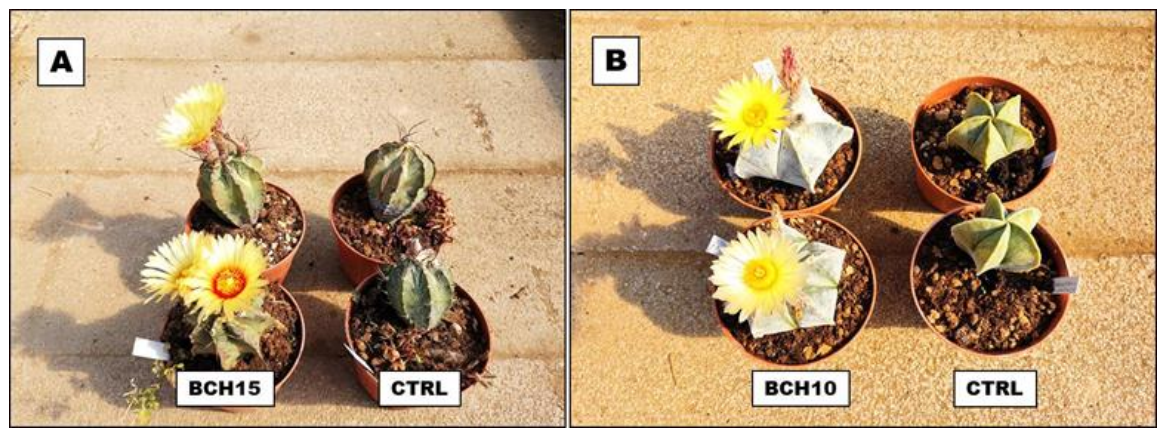

Figure 2 - Effect of biochar on vegetative biomass and flowering of Astrophytum capricorne (A) and Astrophytum myriostigma (B) Legend: (CTRL) control; (BCH15) biochar 15\%; (BCH10) biochar 10\%

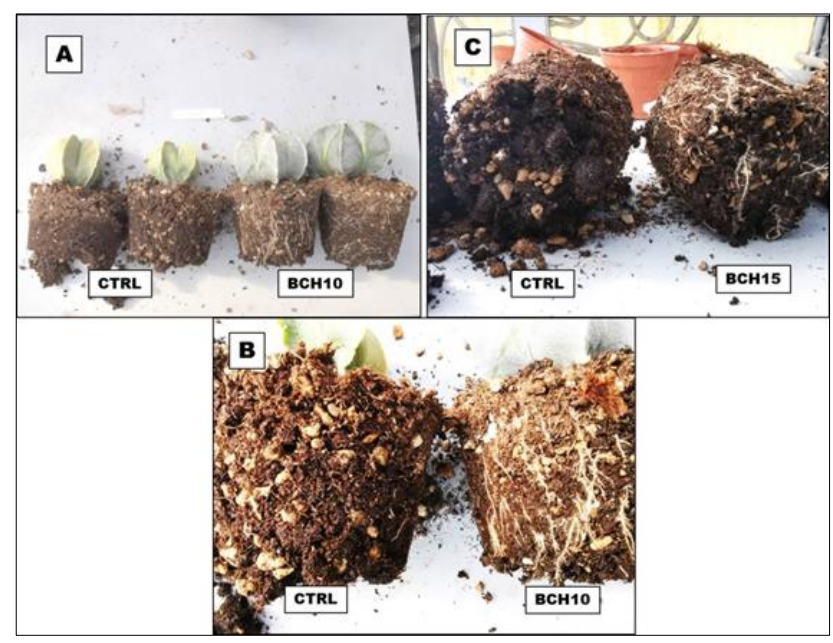

Figure 3 - Effect of biochar on roots biomass of Astrophytum myriostigma (A, B) and Astrophytum capricorne (C) Legend: (CTRL) control; (BCH15) biochar 15\%; (BCH10) biochar 10\%

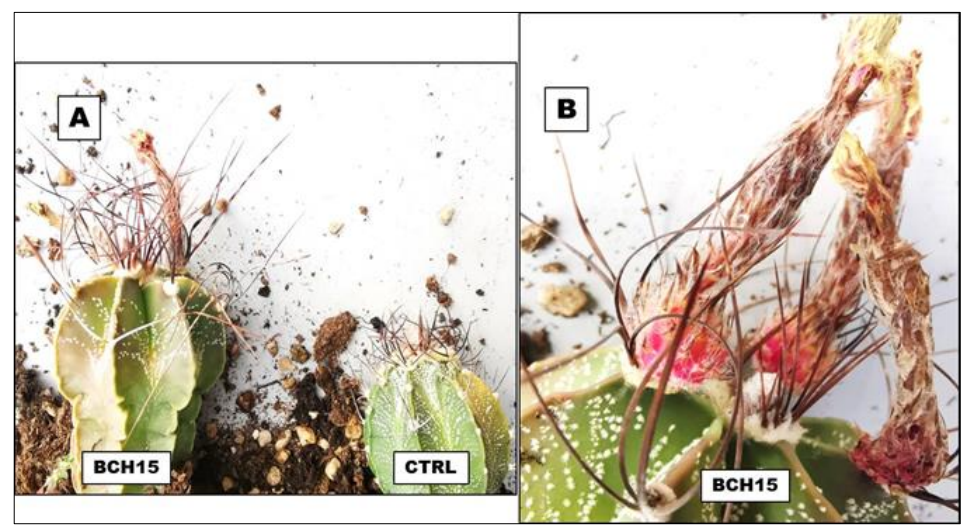

Figure 4 - Effect of biochar on thorns (A) and fruits growth (B) of Astrophytum capricorne Legend: (CTRL) control; (BCH15) biochar 15\% 


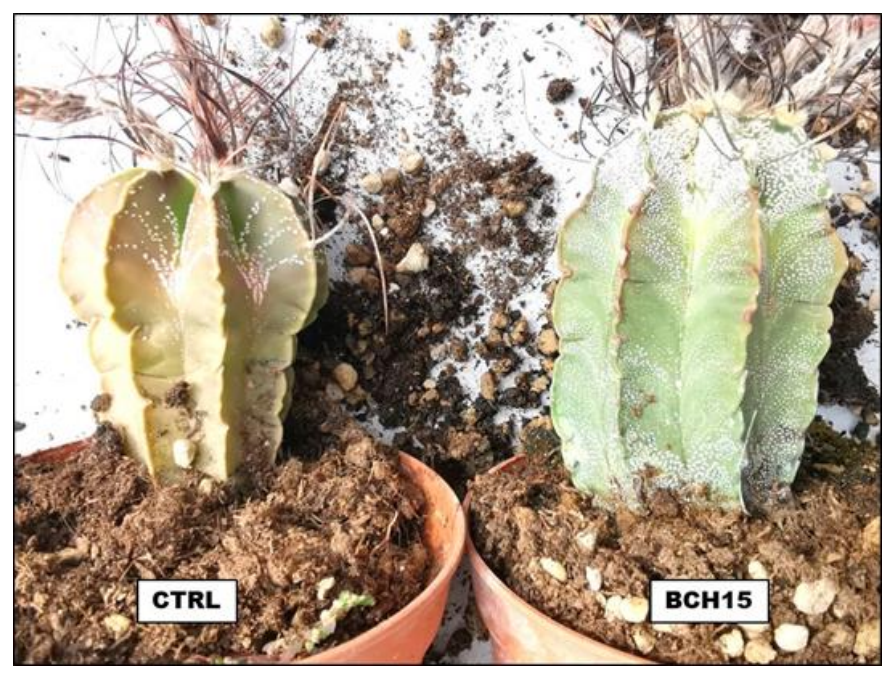

Figure 5 - Effect of biochar on cold stress in Astrophytum capricorne Legend: (CTRL) control; (BCH15) biochar 15\%

\section{Conclusion}

The experimentation carried out at CREA-OF in Pescia showed how the application of biochar to the cultivation substrate of Astrophytum myriostigma and Astrophytum capricorne can significantly improve the quality and the resistance to biotic and abiotic stresses of the plants. As in other experiments in the literature, the application of this soil conditioner also resulted in positive effects in the control of pathogenic fungi, particularly Rhizoctonia solani. This effect was probably mediated by the presence of microorganisms in the biochar that, in addition to having an effect on plant stimulation, may have a fundamental role in their biocontrol activity of substrate pathogens. Interesting results have also been the increase in the number of thorns, flowers and fruit duration and resistance to cold stress in plants grown with biochar. Other investigations are currently in progress to study biostimulant capacities and microbial features present in biochar in other types of cactus, very delicate plants and sensitive to phytopathologies especially in potted cultivations.

\section{Compliance with ethical standards}

\section{Acknowledgments}

The research is part of the project "MicroSuc: microorganisms for the growth and protection of cacti and succulent plants".

\section{Statement of ethical approval}

The present research work does not contain any studies performed on animals/humans subjects.

\section{References}

[1] Cecarini M. Piante grasse. Le succulente non cactacee. Guida pratica completa per coltivare, riconoscere, moltiplicare, difendere, curare le succulente non cactacee. 2011.

[2] Chapman P, Martin M. Cactus e altre succulente. Zanichelli. 1993.

[3] Vázquez-Lobo A, Aguilar Morales G, Arias S, Golubov J, Hernández-Hernández T, Mandujano MC. Systematic Botany. 2015; 40(4): 1022-1030.

[4] Backeberg C. Some results of twenty years of cactus research Part I. A synopsis of the genera of the Cactaceae. Cactus and Succulent Journal. 1950; 22: 181-190.

[5] Britton NL, Rose JN. The Cactaceae vol. 3. Washington, D. C. The Carnegie Institution. 1922. 
[6] Iswaran V, Jauhri KS, Sen A. Effect of charcoal and peat on the yield of moong, soybean and pea. Soil Biology \& Biochemistry. 1980; 12: 191-192.

[7] Wardle DA, Zackrisson 0, Nilsson MC. The charcoal effect in Boreal forests: mechanisms and ecological consequences. Oecologia. 1998; 115: 419-426.

[8] Kishimoto S, Sugiura G. Charcoal as a soil conditioner. In: Symposium on Forest Products Reserarch, International Achievements for the Future. 1985; 5: 12-23.

[9] Major J, Rondon M, Molina D, Riha SJ, Lehmann J. Maize yield and nutrition during 4 years after biochar application to a Colombian savanna oxisol. Plant and Soil. 2010; 333: 117-128.

[10] Rondon MA, Lehmann J, Ramirez J, Hurtado M. Biological nitrogen fixation by common beans (Phaseolus vulgaris L.) increases with bio-char additions. Biology and Fertility of Soils. 2007; 43: 699-708.

[11] Lehmann J, Rillig MC, Thies J, Masiello CA, Hockaday WC, Crowley D. Biochar effects on soil biota - a review. Soil Biology and Biochemistry. 2011; 43: 1812-1836.

[12] Warnock DD, Lehmann J, Kuyper TW, Rillig MC. Mycorrhizal responses to biochar in soil - concepts and mechanisms. Plant and Soil. 2007; 300: 9-20.

[13] Prisa D. Rhizobacteria and zeolites for overcoming saline stress in the cultivation of succulent plants. The International Journal of Engineering and Science (IJES). 2019; 8(5) I: 38-41.

[14] Prisa D. Effective microorganisms for germination and root growth in Kalanchoe daigremontiana. World Journal of Advanced Research and Reviews. 2019; 03(03): 047-053.

[15] Prisa D. Germination of Vegetable and Grassland species With Micronized chabazitic-Zeolites and Endophytic Fungi. IOSR Journal of Agriculture and Veterinary Science (IOSR-JAVS). E-ISSN: 2319-2380, p-ISSN: 2319-2372. May 2019; 12(5): I 32-37.

[16] Jesus ED, Marsh TL, Tiedje JM, Moreira FMD. Changes in land use alter the structure of bacterial communities in Western Amazon soils. ISME Journal. 2009; 3: 1004-1011.

[17] O’Neill B, Grossman J, Tsai MT, Gomes JE, Lehmann J, Peterson J, Neves E, Thies JE. Bacterial community composition in Brazilian Anthrosols and adjacent soils characterized using culturing and molecular identification. Microbial Ecology. 2009; 58: 23-35.

[18] Amonette JE, Joseph S. Characteristics of biochar: Microchemical properties. In: Biochar for Environmental Management: Science and Technology. (Lehmann J., S. Joseph, ed.), Earthscan, London, UK. 2009; 33-52.

[19] Chan KY, Xu Z. Biochar: Nutrient properties and their enhancement. In: Biochar for Environmental Management: Science and Technology. (Lehmann J., S. Joseph, ed.), Earthscan, London, UK. 2009; 67-84.

[20] Blackwell P, Riethmuller G, Collins M. Biochar application to soil. In: Biochar for Environmental Management: Science and Technology. (Lehmann J., S. Joseph, ed.), Earthscan, London, UK. 2009; 207-226.

[21] Prisa D. Effective Microorganisms and Chabazitic-Zeolites for the Improvement Quality of Echinopsis Hybrids. Asian Academic Research Journal of Multidisciplinary. 2019; 6(2): 23-34. 